\title{
RESULTS OF \\ INTRANASAL DACRYOCYSTORHINOSTOMY
}

BY

L. M. JOYCE HENRY,

B.A., M.R.C.S.Eng., F.R.C.S.Edin.

(From the Eye Department of the Royal Infirmary, Edinburgh, under

the charge of A. H. H. SinclaIR, M.D., F.R.C.S.Edin., and E. H.

CAMERON, M.B., F.R.C.S.Edin., and the Ear and Throat Department under the charge of J. S. FRASER, M.B., F.R.C.S.Edin.)

THIs investigation has been carried out in order to test the results obtained by West's operation on the tear sac. During the years 1915 to 1931 (inclusive) 108 such operations have been performed by Dr. J. S. Fraser at the Royal Infirmary, Edinburgh. Of these 108 cases, 77 who live within reasonable distance of Edinburgh were asked to report during July and August, 1932, but only 23 responded. Of these 23 cases four had had bilateral operations, thus giving a total of 27 tear sac operations. Eighteen of the 23 patients were females.

The results of the West operations were studied from three aspects :-

1. Clinical, i.e., the patient's statement regarding her or his condition.

2. Functional efficiency of the new passage from conjunctiva to nose, as tested by the fluorescein test.

3. Bacteriology of conjunctiva: the object here was to ascertain whether the operation could be used for "sterilization" of the conjunctival sac before cataract extraction or other intra-ocular procedures.

1.-Each patient was asked whether she had any watering of the eyes, purulent discharge or other eye trouble : and if the reply was "No" the leading question "Not even in the wind?" was added. Only those cases answering "No" to both questions were put down as fully cured.

(a) Perfect results-no epiphora, $21 \quad$ Per cent.

(b) Imperfect results : epiphora in cold wind, $3 \ldots \quad \ldots \quad 11$ epiphora in bright sunshine, $\begin{array}{lll}1 & \ldots & 3 \cdot 7\end{array}$

(c) No improvement -1 case (bilateral operation) $\quad \ldots \quad 7 \cdot 4$

The last patient apparently had suffered from watering of both eyes from birth and, though the lacrimal passages were patent, had 
had the canaliculi slit, without result, before West's operation was performed.

2.-Fluorescein Test.-This is perhaps mainly of academic interest, for of the four patients showing complete impermeability to the dye, three had no watering of the eyes and the fourth was the congenital bilateral case mentioned above.

Two of the cases showing "some delay" had watering of the eyes in the wind.

(a) Perfect: dye reaches nose in less than two minutes, $19 \quad 70^{\circ} 4$

(b) Imperfect: some delay (2-4 minutes), $3 \quad \ldots \quad \ldots \quad 11.0$

(c) Failure : dye does not pass at all, 4 (one bilateral as $\begin{array}{llllllll}\text { above) } & \ldots & \ldots & \ldots & \ldots & \ldots & \ldots & 18 \cdot 6\end{array}$

3.-Bacteriology.-A swab was taken from the conjunctiva and incubated on fresh blood-smeared agar for two days. Where necessary for purposes of identification, the culture was re-sown on other media. Four conjunctival sacs gave a growth of streptococci, with or without other (innocuous) germs (three of these were cases showing no epiphora and no delay in the fluorescein test, while the fourth had epiphora in a cold wind). No pneumococci were found in this series in spite of the fact that the culture medium chosen was that on which pneumococci grow most readily. Four conjunctival sacs showed Xerosis or coliform organisms (in three of these the drainage was poor or absent, as shown by the fluorescein test, though in all four cases there was complete clinical cure).

Thus only four out of twenty-two eyes examined (five cultures, mostly from "clinical cures" were missed by accident) showed a potentially injurious flora-a "sterilization" rate of 82 per cent. This compares favourably with a bacteriological success-rate of 57 per cent. after external operation, as found by Mattice in Axenfeld's clinic'. Bumke and West ${ }^{2}$ found that "pathological bacteria disappeared from the conjunctival sac within one or two days after West's operation"- - a statement which seems to imply that the immediate (though possibly impermanent) "cleaning up" effect is constantly found. In addition, as Kofler and Urbanek ${ }^{3}$ point out, an external scar and the risk of keloid formation are avoided by West's operation.

\section{Summary}

1.-Twenty-three cases (four after bilateral operation) were investigated.

2.-A perfect clinical result was obtained in $\pi 8$ per cent. (compared with 73 per cent. in $\left.1925^{4}\right)$. 
3.- The fluorescein test may apparently show obstruction in cases with no epiphora and therefore is not of great practical importance.

4.- Sterilization of the conjunctival sac as regards streptococci and pneumococci was obtained in 82 per cent.

\section{REFERENCES}

1. Quoted by West in "Clinical Results of Intranasal Tear-sac Operation." Trans. Ophthal. Amer. Med. Assoc., pp. 69-81, 1931.

2. Ibid.

3. Kofler and Urbanek.-Zur Vereinfachung und Verbesserung der WestPolyak'schen endonasalen Tränen-sackoperation. Wien. Med. Wochenschr., Vol. LXXVIII, p. 632, 1928.

4. Paterson and Fraser.-Brit. Jl. of Ophthal., May, 1919.

Fraser.--Intranasal Dacryocystostomy. Jl. of Laryngol. and Otol., Vol. XL, pp. 725-729, 1925.

\section{A HAND SLIT-LAMP}

BY

\section{N. BISHOP HARMAN}

LONDON

THE value of the standard forms of slit-lamps for certain ophthalmic investigations is undoubted. But the immobility of these large instruments limits their use to the consulting room and clinic.

The hand slit-lamp shown has been devised with the intent of securing an instrument that could be used as readily and as easily as an electric ophthalmoscope; so that it can be carried about, and used with ease for the examination of children, and patients in bed or in their own homes. It cannot, by reason of its small size, compete with the large instruments in magnification and in resolution of fine detail. Yet it will secure a valuable view of the media of the eye as deep as the anterior part of the vitreous. The small lamp as compared with the large might be said to have something like the relation of two-thirds inch objective of the microscope to the one-sixth inch objective. But the small lamp gives the same effect of depth as the large lamp, so that its value for localization is certain.

The lamp is fitted to the battery handle of an electric ophthalmoscope; or a small adapter can be supplied with leads to a torch battery or other suitable source of current. At the upper end, set at right angles to the ophthalmoscope handle, is an eyepiece consisting of a triple achromatic lens giving a linear magnification of $12 \mathrm{X}$. The lens holder is so made that other powered lenses can be substituted. The case of the eyepiece is graven with a 